\title{
Childhood Diffuse Astrocytoma
}

National Cancer Institute

\section{Source}

National Cancer Institute. Childhood Diffuse Astrocytoma. NCI Thesaurus. Code

C114967.

A diffuse astrocytoma that occurs during childhood. 